\title{
Right Cardiac Ventricle Assist Device Procedure
}

National Cancer Institute

\section{Source}

National Cancer Institute. Right Cardiac Ventricle Assist Device Procedure. NCI

Thesaurus. Code C100010.

A procedure involving a mechanical pump which receives blood from the right ventricle and delivers it to the pulmonary artery. (ACC) 